\title{
Resection of orthotopic murine brain glioma
}

\author{
Bingtao Tang1 ${ }^{1}$, Kari Foss ${ }^{2}$, Terence Lichtor ${ }^{3}$, Heidi Phillips ${ }^{2}$, Edward Roy ${ }^{1}$ \\ 'Department of Molecular and Integrative Physiology, University of Illinois at Urbana-Champaign, Urbana, IL 61801, USA. \\ ${ }^{2}$ Department of Veterinary Clinical Medicine, University of Illinois at Urbana-Champaign, Urbana, IL 61802, USA. \\ ${ }^{3}$ Carle Illinois College of Medicine, University of Illinois at Urbana-Champaign, Urbana, IL 61801, USA.
}

Correspondence to: Dr. Edward Roy, Department of Molecular and Integrative Physiology, University of Illinois at UrbanaChampaign, 524 Burrill Hall, 407 S. Goodwin Ave, Urbana, IL 61801, USA. E-mail: eroy@illinois.edu

How to cite this article: Tang B, Foss K, Lichtor T, Phillips H, Roy E. Resection of orthotopic murine brain glioma. Neuroimmuno/ Neuroinflammation 2021;8:64-9. http://dx.doi.org/10.20517/2347-8659.2020.28

Received: 6 Apr 2020 First Decision: 6 Jun 2020 Revised: 22 Jun 2020

Accepted: 1 Jul 2020 Fisrt online: 1 Sep 2020 Published: 21 Mar 2021

Academic Editor: Terry Lichtor, Dale Ding Copy Editor: Cai-Hong Wang Production Editor: Jing Yu

\begin{abstract}
Glioma is a malignant brain tumor with a poor prognosis. Surgical resection is usually the first line of treatment. However, animal models of glioma do not include surgical resection and tumors are typically treated before they become advanced. This report demonstrates the feasibility of surgical resection of advanced gliomas in mice. The described technique establishes a murine model which could be used for the development of immunotherapy for advanced glioma after surgical resection. Use of surgical resection in murine models could increase the probability that therapies developed in mice will translate to human patients.
\end{abstract}

Keywords: Glioma, surgical resection, immunotherapy, overcoming immunosuppression, surgical stress, prolonged survival

\section{INTRODUCTION}

Glioma is a type of brain or spinal cord tumor that originates from glial cells; 80\% of all malignant brain tumors are gliomas ${ }^{[1]}$. These tumors are typically asymptomatic in people until they reach an advanced stage. The standard of care for glioma includes surgery, radiotherapy and chemotherapy. Combining radiotherapy with the chemotherapy agent temozolomide may prolong survival and delay tumor progression modestly ${ }^{[2]}$. Despite the current standard of care, prognosis for glioma patients remains poor: the median survival for high-grade glioma, glioblastoma, is about 12-15 months with only 5\% patients

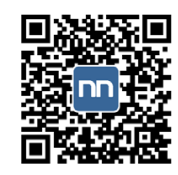


living longer than 5 years $^{[3]}$. These facts indicate that there is a strong need to develop novel treatments for glioma.

Recently, our group developed a novel viro-immunotherapy for early-stage murine glioma with 83\% tumor regression rate ${ }^{[4]}$. Despite the impressive response that this treatment elicits, such a response is not representative of what occurs in the clinical setting, since patients are usually diagnosed at an advanced stage of tumor progression.

Surgical resection has always been the first line of treatment for gliomas. However, surgical resection promotes an immunosuppressive tumor microenvironment ${ }^{[5]}$. It has been reported that interferon- $\gamma$ secretion and cell cytotoxicity of natural killer cells are profoundly suppressed ${ }^{[6]}$; the number of cytotoxic $\mathrm{T}$ cells and $\mathrm{T}$ helper cells ${ }^{[7]}$ markedly decreases, while the number of regulatory $\mathrm{T}$ cells (Tregs) ${ }^{[8,9]}$ and lowdensity neutrophils ${ }^{[10]}$ significantly increases in the postoperative period. All these factors could contribute to the poor prognosis and recurrence of tumor.

As a preliminary step toward testing a novel viro-immunotherapy, we asked whether mice would survive resection of an advanced murine glioma.

\section{METHODS}

\section{Cell culture}

Glioma 261 (GL261) is a murine glioma cell line. GL261 cells were purchased from the National Cancer Institute Division of Cancer Treatment and Diagnosis Repository and tested negative for mycoplasma. Cells were cultured in Dulbecco's Modified Eagle's Medium (DMEM; 10013CV, Corning Incorporated) containing $5 \mathrm{mmol} / \mathrm{L}$ HEPES, $1.3 \mathrm{mmol} / \mathrm{L}$ L-glutamine, $50 \mu \mathrm{mol} / \mathrm{L}$ 2-ME, penicillin, streptomycin and 10\% fetal bovine serum (FBS) at $37{ }^{\circ} \mathrm{C}$ and $5 \% \mathrm{CO}_{2}$. GL261 neurosphere (GL261 NS) cells, which are cancer stem-like non-adherent cells, were generated by culturing in untreated cell culture flasks (08-757-501, Corning Incorporated) with DMEM/F12 + GlutaMAX (10565018, Life Technologies) culture medium containing penicillin/streptomycin (17-602E, Lonza), B27 with vitamin A (17504044, Life Technologies), $20 \mathrm{ng} / \mathrm{mL}$ recombinant human epidermal growth factor (EGF; 236-EG-200, R\&D Systems), $20 \mathrm{ng} / \mathrm{mL}$ recombinant human fibroblast growth factor (FGF; 233-FB-025/CF, R\&D Systems), and $5 \mu \mathrm{g} / \mathrm{mL}$ heparin $\left(\mathrm{H} 3149100 \mathrm{KU}\right.$, Sigma-Aldrich) in an incubator at $37^{\circ} \mathrm{C}$ with $5 \% \mathrm{CO}_{2}^{[11]}$.

\section{Animals}

C57BL/6J mice were purchased from The Jackson Laboratory and maintained as colonies in animal facilities at the University of Illinois Urbana-Champaign. Mice of both sexes were used in experiments when they were 2-3 months old. All animal studies were approved by the Institutional Animal Care and Use Committee (IACUC) at the University of Illinois Urbana-Champaign.

\section{Intracranial tumor establishment}

GL261 NS cells were harvested, washed twice with Hanks' Balanced Salt Solution (HBSS; 21023CV, Corning Incorporated) and stereotactically injected into the brain of mice anesthetized with isoflurane (59399-106-01, Akorn). A total of $5 \times 10^{4}$ GL261 NS cells in $0.5 \mu \mathrm{L}$ HBSS were infused into the ventral striatum ( $0.5 \mathrm{~mm}$ rostral; $2.25 \mathrm{~mm}$ lateral; $3.3 \mathrm{~mm}$ ventral). Mice were euthanized at $75 \%$ of baseline body weight or when they exhibited symptoms of neurological impairment, lethargy, or pain, in accordance with IACUC guidelines.

\section{Intracranial tumor resection}

Tumor-bearing mice were anesthetized with isoflurane (59399-106-01, Akorn) and placed in a stereotactic stage. Mice were treated with a $200-\mu \mathrm{L}$ subcutaneous injection of carprofen $(0.5 \mathrm{mg} / \mathrm{mL}$; Division of 


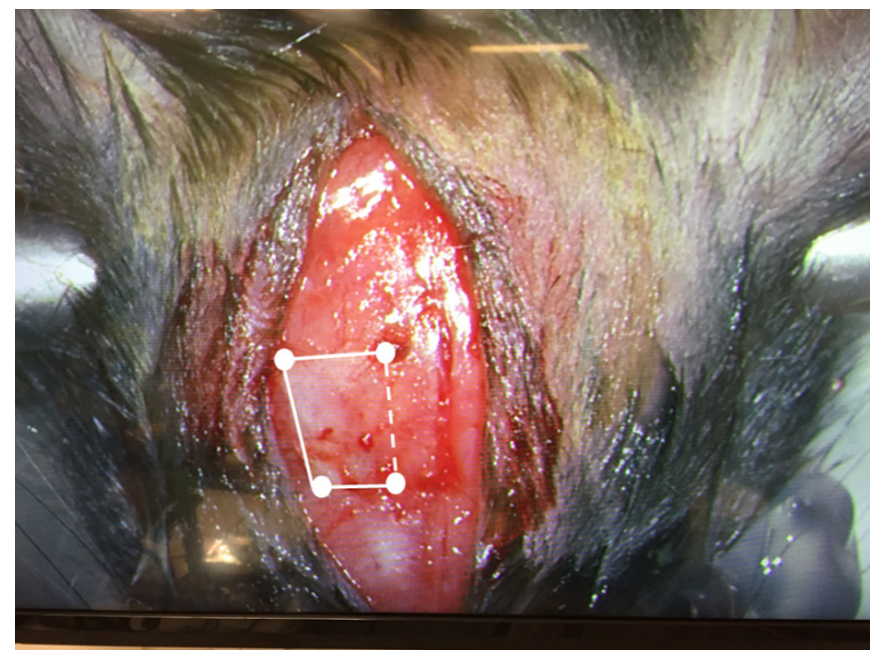

Figure 1. Performance of craniotomy. Four burr holes (white holes) were placed with a hand-held Jacob's chuck. A craniotomy was then performed by cutting into the skull with micro-scissors and connecting the small burr holes with the base of the flap positioned medially (dashed line)

Animal Resources, University of Illinois at Urbana-Champaign). Surgery was performed by experienced neurosurgeons (KF and TL), using a Zeiss Opmi Visu Operating Microscope with 200-mm working distance and 10-25 $\times$ magnification. Microsurgical instruments were obtained from Accurate Surgical and Scientific Instruments. A linear incision was made in a para-sagittal direction on the dorsum of the skull with a \#15 scalpel blade. The skin was reflected laterally, and the peri-cranium was exposed with cotton swabs. The bregma and sagittal suture were identified, and a craniotomy procedure was performed just lateral to the sagittal suture over the location of interest (site of GL261 glioma cells). Four small burr holes (white holes shown in Figure 1) were created in the bone using a hand-held Jacob's chuck. Using microscissors to cut the bone, three of the four sides (white solid line shown in Figure 1) of the craniotomy were opened with the fourth side (white dashed line shown in Figure 1) remaining attached to create a bone flap. The overlying dura was opened with micro-scissors and gently peeled back from the cortical surface over the site of the tumor. Using micro-dissection under a high-power microscope, an attempt was made to remove as much of the tumor mass as possible using a combination of blunt and sharp dissection, while minimizing damage to normal neural tissue. Tumor was identified by darker coloration and gelatinous texture. No fluorescent dye was used to visualize tumor. Following tumor removal, the extirpated tumor bed was copiously irrigated, and hemostasis was ensured. The bone flap was placed gently back over the exposed brain. PBS containing penicillin $(1000 \mathrm{U} / \mathrm{mL})$ and streptomycin $(1 \mathrm{mg} / \mathrm{mL})(17-602 \mathrm{E}$, Lonza) was used to irrigate the craniotomy. The skin was closed with cyanoacrylate glue (VetBond; 1469SB; 3M).

\section{HE staining}

After mice were euthanized, brains were snap-frozen in OCT embedding medium (23-730-571, Fisher Healthcare) for cryosectioning. Cryosections $(5 \mu \mathrm{m})$ were fixed in cold $95 \%$ ethanol overnight and stained with hematoxylin and eosin.

\section{Data analysis}

GraphPad Prism software (La Jolla, CA) was used for all statistical analyses and graph presentation. Survival data were recorded from the time of the tumor cell implantation until euthanasia and were plotted using a Kaplan-Meier curve. Survival treatment groups were compared with a Log-rank (Mantel-Cox) test. $P<0.05$ was considered significant. 


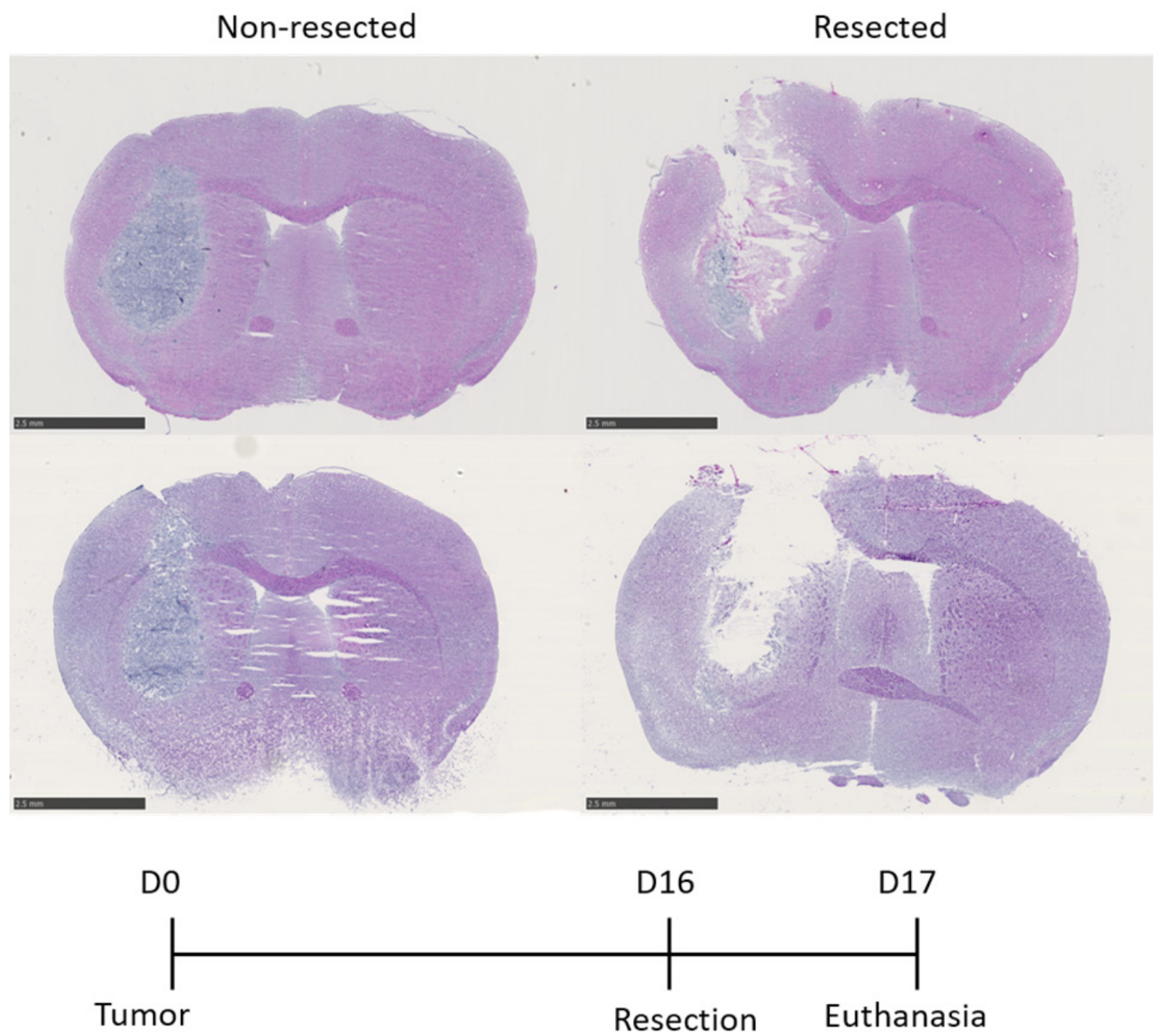

Figure 2. Efficacy of tumor resection shown by $\mathrm{HE}$ staining. Mice received tumor cells (i.c.) on day $\mathrm{O}$, and tumor resection occurred on day 16. Mice were euthanized on day 17 , followed by overnight incubation of tissue sections in $95 \%$ ethanol and standard $\mathrm{HE}$ staining protocol. Representative HE stained sections are shown. Pink: normal brain tissue; dark blue: tumor. Scale bar $=2.5 \mathrm{~mm}, n=2$ for both groups

\section{RESULTS}

\section{Resection of tumor on live mice is feasible and has the potential to prolong survival for mice bearing advanced glioma}

A technique was developed to perform tumor resection on live mice bearing advanced glioma in the brain. Glioma tumors were established by direct intracranial injection of $5 \times 10^{4}$ GL261 NS cells/mouse into the right striatum. Tumor resection was performed 16 days after tumor implantation. Four mice were euthanized on day 17 for HE staining, and the remaining four mice were reserved for the survival experiment. Figure 2 shows that the advanced glioma occupied about 25\% of area of the right hemisphere of the brain and that surgical resection removed approximately $85 \%$ of the glioma tumor. The survival curve [Figure 3] shows that the median survival for resected mice was prolonged by 5 days (although short of significant difference) compared to non-resected mice. These results indicate that it is feasible to perform tumor resection on mice bearing advanced glioma in the brain, that mice are able to survive the resection, and that surgical resection has the potential to prolong survival time. 

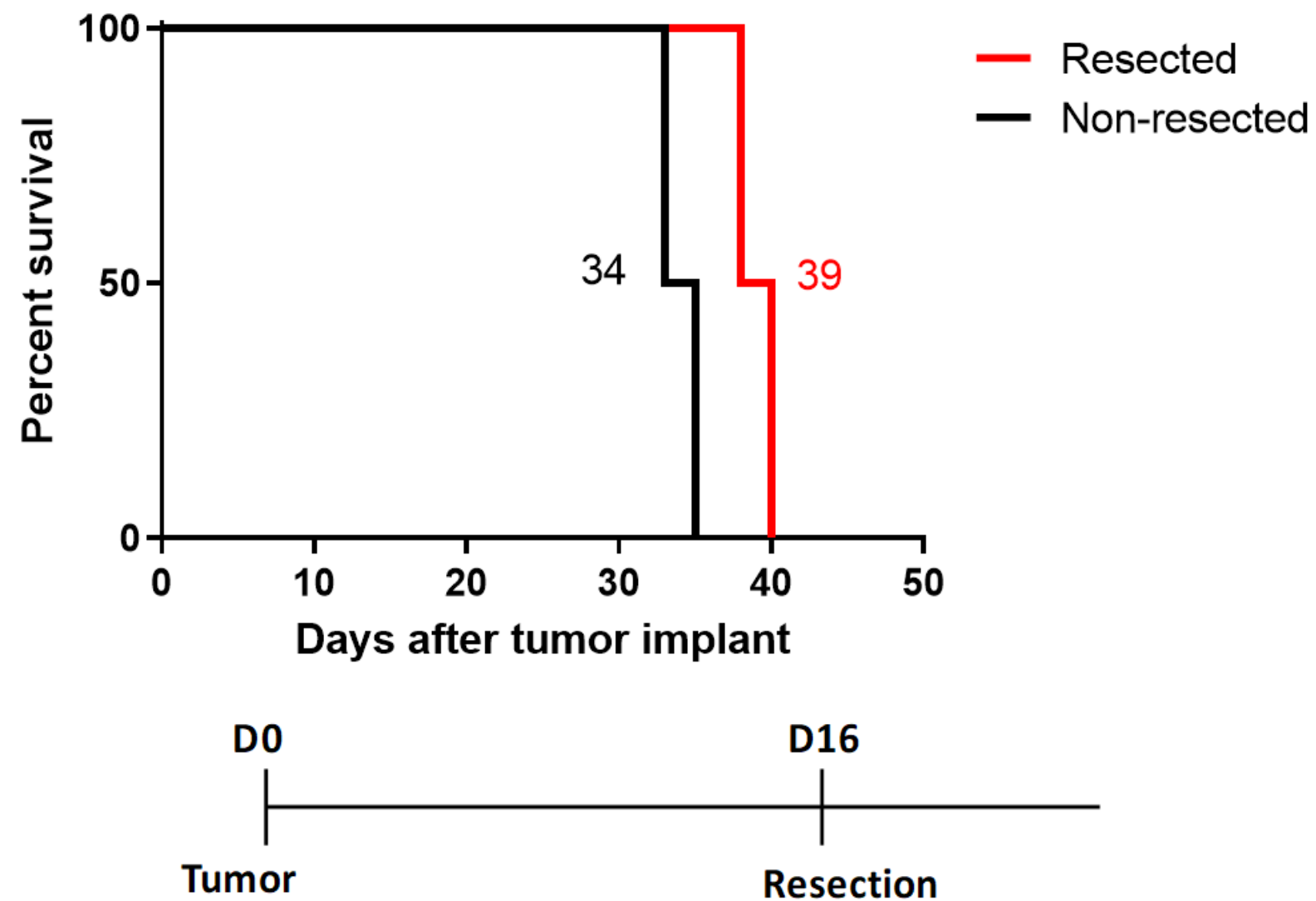

Figure 3. Prolonged survival of mice bearing advanced glioma after tumor resection. Mice received tumor (i.c.) on day 0 , and tumor resection was on day 16 . Mice that received the tumor resection lived longer (but short of statistical significance, $P=0.0896$ ) than mice that did not receive tumor resection, $n=2$ for both groups

\section{DISCUSSION}

Gliomas infiltrate the brain, and therefore, it is difficult to differentiate tumor tissue from normal brain. Magnetic resonance imaging (MRI) of tumors before surgical resection could help guide how aggressive removal of tissue should be. Intraoperative MRI in humans can be performed, but is not yet practical in mice. Aggressive surgical resection can lead to neurologic deficits. No neurologic deficits were observed in the animals in this study. Future work will determine whether resection as described combined with an immunotherapy strategy will lead to a prolongation of survival without adverse side effects. Since surgical stress can be immunosuppressive, including resection will provide a more rigorous test of potential immunotherapies.

\section{DECLARATIONS}

\section{Acknowledgments}

We thank the following: Dr. David Kranz for generously sharing his laboratory facilities; people of the Division of Animal Resources at University of Illinois Urbana-Champaign for cheerful and competent service; and Claire Schane and David Yan for technical assistance.

\section{Authors' contributions}

Concept and design: Tang B, Roy E

Data acquisition, analysis and interpretation: Tang B, Foss K, Lichtor T, Phillips H, Roy E

Manuscript preparation: Tang B, Roy E

Critical revision and finalizing of the manuscript: Foss K, Lichtor T, Phillips H, Roy E 


\section{Availability of data and materials}

Not applicable.

\section{Financial support and sponsorship}

This research was funded by the Carle Foundation Hospital and University of Illinois Cancer Scholars for Translational and Applied Research (C`STAR) Graduate Program.

\section{Conflicts of interest}

All authors declared that there are no conflicts of interest.

\section{Ethical approval and consent to participate}

All experiments were approved in advance by the Institutional Animal Care and Use Committee of the University of Illinois (protocol 19002), whose animal programs are accredited by the AAALAC International and follow the NRC Guide for the Care and Use of Laboratory Animals, Eighth Edition.

\section{Consent for publication}

Not applicable.

\section{Copyright}

(c) The Author(s) 2021.

\section{REFERENCES}

1. Goodenberger ML, Jenkins RB. Genetics of adult glioma. Cancer Genet 2012;205:613-21.

2. Hart MG, Garside R, Rogers G, Stein K, Grant R. Temozolomide for high grade glioma. Cochrane Database Syst Rev 2013;(4):CD007415.

3. Ostrom QT, Gittleman H, Liao P, Rouse C, Chen Y, et al. CBTRUS statistical report: primary brain and central nervous system tumors diagnosed in the United States in 2007-2011. Neuro Oncol 2014;16 Suppl 4:iv1-63.

4. Tang B, Guo ZS, Bartlett DL, Yan DZ, Schane CP, et al. Synergistic combination of oncolytic virotherapy and immunotherapy for glioma. Clin Cancer Res 2020;26:2216-30.

5. Chen Z, Zhang P, Xu Y, Yan J, Liu Z, et al. Surgical stress and cancer progression: the twisted zo. Mol Cancer 2019;18:132.

6. Angka L, Martel AB, Kilgour M, Jeong A, Sadiq M, et al. Natural killer cell IFN $\gamma$ secretion is profoundly suppressed following colorectal cancer surgery. Ann Surg Oncol 2018;25:3747-54.

7. Ogawa K, Hirai M, Katsube T, Murayama M, Hamaguchi K, et al. Suppression of cellular immunity by surgical stress. Surgery 2000;127:329-36.

8. Lissoni P, Brivio F, Fumagalli L, Messina G, Meregalli S, et al. Effects of the conventional antitumor therapies surgery, chemotherapy, radiotherapy and immunotherapy on regulatory T lymphocytes in cancer patients. Anticancer Res 2009;29:1847-52.

9. Saito Y, Shimada M, Utsunomiya T, Morine Y, Imura S, et al. Regulatory T cells in the blood: a new marker of surgical stress. Surg Today 2013;43:608-12.

10. Kumagai Y, Ohzawa H, Miyato H, Horie H, Hosoya Y, et al. Surgical stress increases circulating low-density neutrophils which may promote tumor recurrence. J Surg Res 2020;246:52-61.

11. Pellegatta S, Finocchiaro G. Dendritic cell vaccines for cancer stem cells. In: Yu JS, editor. Cancer Stem Cells. Totowa: Humana Press; 2009. pp. 233-47. 